\title{
Chemical and Bioactive Features of Amaranthus caudatus L. Flowers and Optimized Ultrasound-Assisted Extraction of Betalains
}

\author{
Custódio Lobo Roriz ${ }^{1,2}$, Virginie Xavier ${ }^{1}$, Sandrina A. Heleno ${ }^{1, *}$, José Pinela ${ }^{1} \mathbb{D}$, Maria Inês Dias ${ }^{1} \mathbb{D}$, \\ Ricardo C. Calhelha $^{1}(\mathbb{D})$, Patricia Morales ${ }^{2}$ (D) , Isabel C. F. R. Ferreira ${ }^{1}$ (D) and Lillian Barros ${ }^{1, *(D)}$
}

1 Centro de Investigação de Montanha (CIMO), Instituto Politécnico de Bragança, Campus de Santa Apolónia, 5300-253 Bragança, Portugal; cmlobo@ipb.pt (C.L.R.); virginie.xavier@ipb.pt (V.X.); jpinela@ipb.pt (J.P.); maria.ines@ipb.pt (M.I.D.); calhelha@ipb.pt (R.C.C.); iferreira@ipb.pt (I.C.F.R.F.)

2 Departamento de Nutrición y Ciencia de los Alimentos, Facultad de Farmacia, Universidad Complutense de Madrid (UCM), Pza Ramón y Cajal s/n, E-28040 Madrid, Spain; patmoral@ucm.es

* Correspondence: sheleno@ipb.pt (S.A.H.); lillian@ipb.pt (L.B.)

\section{check for} updates

Citation: Roriz, C.L.; Xavier, V.; Heleno, S.A.; Pinela, J.; Dias, M.I.; Calhelha, R.C.; Morales, P.; Ferreira, I.C.F.R.; Barros, L. Chemical and Bioactive Features of Amaranthus caudatus L. Flowers and Optimized Ultrasound-Assisted Extraction of Betalains. Foods 2021, 10, 779. https:// doi.org/10.3390/foods10040779

Academic Editors: Antonio De Haro Bailón and Fernando Cámara-Martos

Received: 2 March 2021

Accepted: 30 March 2021

Published: 5 April 2021

Publisher's Note: MDPI stays neutral with regard to jurisdictional claims in published maps and institutional affiliations.

Copyright: (C) 2021 by the authors Licensee MDPI, Basel, Switzerland. This article is an open access article distributed under the terms and conditions of the Creative Commons Attribution (CC BY) license (https:// creativecommons.org/licenses/by/ $4.0 /)$

\begin{abstract}
The vibrant colours of many plants are due to secondary metabolites, such as nitrogencontaining compounds, where betacyanins are included. These compounds can be found in plants such as Amaranthus caudatus L. that, due to their high nutritional benefits, have been overproduced, which leads to the accumulation of large amounts of bio-residues. Among these bio-residues, the flowers which have a very intense pink colour and present no economic value or subsequent destination can be exploited as sources of natural colouring agents (betacyanins). This work aimed at characterising the flower's extract in terms of bioactive molecules such as tocopherols, organic acids, but essentially in terms of betacyanins, in order to obtain a natural colouring agent. For the extraction, ultrasound-assisted extraction (UAE) ideal conditions were obtained using the Response Surface Methodology (RSM), allowing the attainment of an enriched extract of betacyanins in high yields and purity. The obtained extracts were analysed for their bioactive potential, namely antioxidant, antimicrobial and cytotoxic properties. From the obtained results, three isoforms of tocopherols were detected, $\beta$-tocopherol $(0.884 \pm 0.003 \mathrm{mg} / 100 \mathrm{~g}$ dry weight $(\mathrm{dw}))$ being the most abundant one. Regarding the organic acids, oxalic $(2.48 \pm 0.05 \mathrm{mg} / 100 \mathrm{~g} \mathrm{dw})$, shikimic $(0.170 \pm 0.003 \mathrm{mg} / 100 \mathrm{~g}$ $\mathrm{dw})$ and traces of fumaric acid were found. Four betacyanins were identified and quantified, namely: amaranthine (171 $\pm 1 \mathrm{mg} / \mathrm{g}$ extract), isoamaranthine (38 $\pm 1 \mathrm{mg} / \mathrm{g}$ extract), betanin $(1.6 \pm 0.1 \mathrm{mg} / \mathrm{g})$, and isobetanin $(1.3 \pm 0.1 \mathrm{mg} / \mathrm{g}$ extract). The obtained extract also presented antioxidant activity with inhibition concentration ( $\mathrm{IC}_{50}$ values) of $29.0 \pm 0.4 \mu \mathrm{g} / \mathrm{mL}$ and $114 \pm 4 \mu \mathrm{g} / \mathrm{mL}$ for $\Delta t$ of $60 \mathrm{~min}$ and $120 \mathrm{~min}$, respectively in the oxidative haemolysis inhibition assay (OxHLIA) assay. The obtained extract also presented an interesting antibacterial activity with minimum inhibitory concentrations ranging from 5 to $20 \mathrm{mg} / \mathrm{mL}$ against pathogenic bacteria and revealed no toxicity for normal cells.
\end{abstract}

Keywords: Amaranthus caudatus L.; bioactive compounds; betacyanins; natural colorants; extraction process optimisation

\section{Introduction}

Secondary metabolites in the plant kingdom are natural products resulting from the primary metabolism responsible for various physiological functions. These molecules are accountable for the strong interaction of plants with the surrounding environment, ensuring their survival [1]. Plants have many different strategies to survive and ensure their propagation, such as attractive odours, or vibrant colours in their flowers and fruits. These vibrant colours result from the expression of some molecules from secondary metabolism, that act as a gimmick, attracting different animals responsible for pollinating them [2].

One of the most important classes of molecules present in plants is nitrogen-containing compounds, including betalains, that are alkaloids responsible for the intense colours of 
several flowers and fruits of the Caryophyllales [3,4]. Unlike anthocyanins, betalains are not dispersed by a huge range of plant species [4], but they can be found in different plant tissues of flowers, fruits, stems, leaves and even in seeds [5]. Betacyanins, a more specific subgroup of betalains, are responsible for the bright pink colour of the plants, aiming at attracting different animals as pollinating or seed dispersing agents [6]. These secondary metabolites have been extensively explored, due to the exhaustive search of the industry for natural colouring agents, caused by the recent limitations imposed by legislators regarding the side effects of artificial compounds and also due to the consumer's demand for safer and healthier products [7].

Amaranthus caudatus L. has gained special attention in recent years due to the nutritional profile of its seeds [8], and also to numerous bioactivities responsible for the therapeutic potential of this species [9]. The significant increase in the production of this plant led to the accumulation of high amounts of by-products, such as the pink flowers that have no valuable destination. These flowers present a strong pink colour that can be exploited as sources of natural colouring agents (betacyanins) for industrial application, giving an economically viable destination for these by-products. In addition to the interesting colouring power presented by betacyanins, this compounds can be associated with many biological properties such as antioxidant, hypoglycaemic and hypolipidemic action, antimicrobial activity [10], which make the obtained colouring extract, safer, healthier and functional [11]. In the literature it is possible to witness the growing amount of information regarding these compounds and their extraction methodologies [12]. Some examples of alternative sources of these compounds are the flowers of Gomphrena globosa [12], and Bougainvillea glabra [13], as well as fruits of Hylocereus spp. [14]. Their extraction can be carried out by numerous methodologies and, for instance, it is possible to find in the literature authors exploring the recovery of these compounds with extraction by maceration [15], microwave-assisted extraction [16] and ultrasound-assisted extraction [14,16], this last one being very interesting and showing the most promising results.

Bearing this in mind, the present work aims at exploiting the flowers of $A$. caudatus as a source of bioactive (tocopherols and organic acids), but specially of colouring compounds (betacyanins).

Ultrasound assisted extraction (UAE) was applied and optimised through the Response surface methodology (RSM), a statistical tool widely used in the optimisation of extraction processes, which allows the evaluation of several factors that affect the extractability and stability of the target molecules and already applied to the UAE technique, in order to recover colouring agents from the same family [16]. Moreover, the bioactive potential of these extracts will also be evaluated through the antioxidant and antimicrobial potential, as well as the hepatotoxicity for normal cells.

\section{Materials and Methods}

\subsection{Plant Samples}

Samples of Amaranthus caudatus L. were supplied by the company "Cantinho das Aromáticas" (Portugal), an enterprise located in Vila Nova de Gaia, Portugal that commercialises aromatic and medicinal plants. This company has a vast certified collection of plant materials of local and exotic origin and applies sustainable organic farming practices. The botanical identification was made by the botanical specialist responsible for the collection of medicinal plants in the herbarium of Escola Superior Agrária (BRESA) of the Polytechnic Institute of Bragança, Portugal. The A. caudatus flowers were manually separated from the rest of the plant, lyophilised (FreeZone 4.5, Labconco, Kansas City, MO, USA), grounded to 20 mesh, and kept in a container protected from light and humidity at $-20{ }^{\circ} \mathrm{C}$ until further analysis.

\subsection{Colour Measurement}

The colour of the lyophilised flower sample was measured with a colorimeter (model CR-400, Konica Minolta Sensig Inc., Tokyo, Japan) previously calibrated against a standard 
white tile, equipped with an iluminant $C$ and an 8 -mm diaphragm aperture. The CIE $L^{*}$ (lightness), $a^{*}$ (greenness-redness), and $b^{*}$ (blueness-yellowness) colour space values were recorded using a Spectra Magic Nx software (version CM-S100W 2.03.0006)

\subsection{Chemical Characterisation}

\subsubsection{Organic Acids}

For organic acids extraction, $1 \mathrm{~g}$ of flower samples was extracted with $25 \mathrm{~mL}$ of metaphosphoric acid at $4.5 \%$ solution, that was then filtered $(0.22-\mu \mathrm{m}$ disposable filters), for further analysis. Organic acids were analysed by ultra-fast liquid chromatography (UFLC), as previously described by Pereira et al. (2013) [17], through a UFLC system, in the following operating conditions: system: Shimadzu 20 A series UFLC (Shimadzu Corporation, Kyoto, Japan); column: SphereClone (Phenomenex, Torrance, CA, USA) reverse phase $\mathrm{C} 18$ column $(5 \mu \mathrm{m}, 250 \mathrm{~mm} \times 4.6 \mathrm{~mm}$ i.d.); detector: PDA Shimadzu detector; mobile phase: $3.6 \mathrm{mM}$ sulphuric acid; flux: $0.8 \mathrm{~mL} / \mathrm{min}$; wavelength: $215 \mathrm{~nm}$; temperature: $35^{\circ} \mathrm{C}$; software: LabSolutions, LCsolutions Version 1.25.

Alongside this, the quantification of the detected organic acids, was carried out by comparing the area of the peaks with the calibration curves obtained from commercial standards of each of the compounds, and the results were expressed in g per $100 \mathrm{~g}$ of dry weight $(\mathrm{dw})$.

\subsubsection{Tocopherols}

For the extraction of tocopherols, $500 \mathrm{mg}$ of flower sample was used, to which was added tocol (IS) and butylated hydroxytoluene (BHT, protective antioxidant of the tocopherols). To this mixture, methanol, hexane and a concentrated $\mathrm{NaCl}$ solution were added. After phase separation, the upper portion was collected, evaporated in a nitrogen stream and re-dissolved in hexane, and filtered (0.22 $\mu \mathrm{m}$ disposable filters), for further analysis. The profile in tocopherols was determined following an analytical procedure previously described by Barros et al. (2013) [18], through an HPLC equipment operating in the following conditions: system: pump (Knauer, Smartline system 1000, Berlin, Germany), degasser system (Smartline manager 5000), autosampler (Jasco AS-2057, Easton, MD, USA); column: Polyamide II ( $250 \mathrm{~mm} \times 4.6 \mathrm{~mm}$ i.d.) normal-phase column from YMC Waters (Dinslaken, Germany); detector: fluorescence detector (Jasco FP-2020, Easton, Maryland, MD, USA); mobile phase: hexane and ethyl acetate (70:30, $v / v)$; flux: $1 \mathrm{~mL} / \mathrm{min}$; wavelength: excitation at $290 \mathrm{~nm}$ and emission at $330 \mathrm{~nm}$; temperature: $35^{\circ} \mathrm{C}$; software: DataApex Clarity, Version 2.4.1.43.

The calibration curves obtained for commercial standards for each of the compounds allowed the quantification of the detected compounds, using the internal standard methodology (IS-tocol), with the results expressed in mg per $100 \mathrm{~g}$ of dry weight (dw).

\subsubsection{Betacyanins}

For the chromatographic analysis of the betacyanins profile, $1.5 \mathrm{~mL}$ of extract solution recovered from the flower samples was obtained by ultrasound assisted extraction using distilled water as solvent in the conditions of a solid/liquid ratio of $5 \mathrm{~g} / \mathrm{L}$, time $-22 \mathrm{~min}$ and power of $500 \mathrm{~W}$, in an ultrasonic system (ultrasonic homogeniser, model CY-500, Optic Ivymen Systen, Barcelona, Spain; $20 \mathrm{kHz}$ frequency) equipped with a titanium probe [16]. Afterwards, this extract was filtered through a $0.22-\mu \mathrm{m}$ disposable syringe filter and injected onto a Dionex Ultimate 3000 HPLC system (Thermo Scientific, San Jose, CA, USA), operating under the conditions described by Roriz et al. (2018) [10]. Compounds were detected with a diode detector (DAD) at $530 \mathrm{~nm}$ wavelength. Chromatographic data were obtained and processed using Xcalibur software (Thermo Finnigan, San Jose, CA, USA). The detected betacyanins were characterised based on their UV-Vis and mass spectrum and quantified using the calibration curve for Gomphrenin III $(y=14,670 \times-19,725$, $\left.R^{2}=0.9997\right)$. The results were expressed in $\mathrm{mg}$ per $\mathrm{g}$ of extract. 


\subsection{Evaluation of Bioactive and Colouring Properties}

The extract obtained according to the description stated in Section 2.4.3. was centrifuged at $480 \mathrm{~g}$ for $10 \mathrm{~min}$ and the supernatant was carefully collected and lyophilised. The colour of the obtained extract was measured as described in Section 2.3.

\subsubsection{Evaluation of the Anti-Haemolytic Activity}

The antioxidant capacity of $A$. caudatus flower extract was assessed by the oxidative haemolysis inhibition assay (OxHLIA), following a method described by Silva de Sá et al. (2019) [19]. Briefly, an erythrocyte solution $(2.8 \%, v / v ; 200 \mu \mathrm{L})$ in phosphate-buffered saline (PBS, pH 7.4) was mixed with $400 \mu \mathrm{L}$ of either: (i) extract solution $(18.75-600 \mu \mathrm{g} / \mathrm{mL}$ in PBS), (ii) PBS (control), (iii) water (for complete haemolysis), or (iv) trolox (7.81-250 $\mu \mathrm{g} / \mathrm{mL}$ PBS). After pre-incubation at $37^{\circ} \mathrm{C}$ for $10 \mathrm{~min}$ with shaking, $200 \mu \mathrm{L}$ of $2,2^{\prime}$-azobis(2methylpropionamidine) dihydrochloride (AAPH, $160 \mathrm{mM}$ in PBS, from Sigma-Aldrich) were added and the optical density was measured at $690 \mathrm{~nm}$ every $~ 10 \mathrm{~min}$ in a microplate reader (Bio-Tek Instruments, ELX800) until complete haemolysis. Results were expressed as $\mathrm{IC}_{50}$ values $(\mu \mathrm{g} / \mathrm{mL})$ for $\Delta t$ of 60 and $120 \mathrm{~min}$.

\subsubsection{Antibacterial Activity}

To access the antibacterial activity of the extract, different bacteria consisting of clinical isolates of patients from hospital units in North-eastern Portugal were used. Five Gramnegative (Escherichia coli, Klebsiella pneumoniae, Morganella morganii, Pseudomonas aeruginosa, and Proteus mirabilis) and three Gram-positive (methicillin-resistant Staphylococcus aureus (MRSA), Listeria monocytogenes, and Enterococcus faecalis) bacteria were tested. The microdilution method and the rapid $p$-iodonitrotetrazolium chloride (INT; Panreac Applichem, Barcelona, Spain) colorimetric assay were performed following the procedures described by Pires et al. (2018) [20] with some modifications. For each inoculum, one positive control was prepared with bacteria and Mueller-Hinton broth (MHB; Biolab, Budapest, Hungary). A solution prepared with MHB or tryptic soy broth (TSB; Biolab, Budapest, Hungary), one with the extract only, and the last one with medium and antibiotic (vancomycin, imipenem, or ampicillin), were used as negative controls. Minimum inhibitory concentrations (MICs, $\mathrm{mg} / \mathrm{mL}$ ), which represent the lowest extract concentration that inhibits the visible bacterial growth, and minimum bactericidal concentrations $(\mathrm{MBCs}, \mathrm{mg} / \mathrm{mL}$ ), corresponding to the lowest extract concentration required to kill a particular bacterium, were the units in which the results were expressed.

\subsubsection{Cytotoxicity to Normal Cells}

The extract was tested for potential toxicity to normal cells, namely a porcine liver primary culture (PLP2), through the sulforhodamine B assay, as described by Guimarães et al. (2013) [21]. The extract was tested in a range of concentrations from 400 to $1.56 \mu \mathrm{g} / \mathrm{mL}$, allowing the determination of the extract concentration providing $50 \%$ of cell growth inhibition $\left(\mathrm{GI}_{50}, \mu \mathrm{g} / \mathrm{mL}\right)$. Ellipticine was used as a positive control.

\subsection{Optimisation of the Betalains Extraction Using Response Surface Methodology}

\subsubsection{Experimental Design for Extraction Process Optimisation}

A five-level central composite design (CCD) coupled with RSM was implemented to optimise the extraction of betacyanins from A. caudatus flowers. The coded and real values of the independent variables $X_{1}$ (time: $t, \min$ ) and $X_{2}$ (ultrasonic power: $p, W$ ) are presented in Supplementary Material Table S1. These variables and their range of values were selected based on a previous study of Rocha et al. [17]. The ultrasonic power covered the minimum and maximum values allowed by the ultrasonic equipment, while times greater than $45 \mathrm{~min}$ are not feasible due to possible degradation phenomena. Design-Expert software, Version 11 (Stat-Ease, Inc., Minneapolis, MN, USA) was used to generate the 18 experimental points of the design, which included 4 factorial points, 4 axial or star points 
replicated two times, and 6 points replicated at the centre of the experimental domain. The experimental runs were randomised to minimise the effects of unexpected variability.

\subsubsection{Ultrasound-Assisted Extraction}

The UAE was performed using the ultrasonic system referred to above. A known weight $(\sim 2.5 \mathrm{~g})$ of flower sample was placed in a beaker with $50 \mathrm{~mL}$ of distilled water and processed according to the experimental design, where different levels of $t(1-45 \mathrm{~min})$ and $P(5-500 \mathrm{~W})$ were combined. The solid/liquid ratio was kept at $50 \mathrm{~g} / \mathrm{L}$, as well as the temperature $\left(25-35^{\circ} \mathrm{C}\right.$; a water bath was used to avoid increasing the temperature). After extraction, the mixtures were centrifuged at $480 \mathrm{~g}$ for $10 \mathrm{~min}$ and the supernatants were carefully collected. An aliquot of each supernatant was used to determine the extraction yield (extract weight, $\%, w / w$ ) and the remainder was used for quantification of betalains (mg/g plant material), as described in Section 2.4.3.

\subsubsection{Extraction Process Modelling and Statistical Analysis}

The response variables $Y_{1}$ (extraction yield), $Y_{2}$ (amaranthine content), $Y_{3}$ (isoamaranthine content), and $Y_{4}$ (total betacyanins content, resulting from the sum of all detected betacyanins) were used to optimise the recovery of betacyanins from A. caudatus flower. Fitting procedures, coefficient estimates, and statistical analysis of the polynomial model equations were performed using Design-Expert software as previously described [22].

\subsection{Statistical Analysis}

The experiments were carried out in triplicate and the results were expressed as the mean \pm standard deviation (except for antibacterial activity). For colour and antioxidant activity analyses, the SPSS Statistics Software (IBM SPSS Statistics for Windows, Version 22.0. Armonk, NY, USA: IBM Corp.) was used to assess significant differences among two samples by applying a two-tailed paired Student's $t$-test (significance of 0.001 ).

\section{Results and Discussion}

\subsection{Colour Parameters}

The results of the colour parameters $L^{*}$ (lightness), $a^{*}$ (redness), and $b^{*}$ (yellowness) measured in the A. caudatus flower sample and in its extract are presented in Table 1 , as well as the results of their conversion to RGB values that visually illustrate the colour shades. It was possible to observe a significant difference between the two samples. The extract presented a lower $L^{*}$ value and a higher $a^{*}$ value, thus showing a darker and reddish colour shade. In addition, the parameter $b^{*}$ indicated that the flower sample was more yellow than the extract. Overall, the colour was intensified after extraction, as expected, due to a concentration of betacyanin pigments, resulting in an intense purple colour. Thus, statistically significant differences in the colour parameters of the flower and the extract, can be verified $(p$-value $<0.001)$.

Table 1. Colour parameters of the lyophilised flower sample and its extract, according to the CIELAB colour space and the RGB scale.

\begin{tabular}{|c|c|c|c|c|c|c|c|}
\hline & \multicolumn{3}{|c|}{ CIELAB } & \multicolumn{3}{|c|}{ RGB } & \multirow{2}{*}{ Colour } \\
\hline & $L^{*}$ & $a^{*}$ & $b^{*}$ & $\mathbf{R}$ & G & B & \\
\hline $\begin{array}{l}\text { Flower } \\
\text { sample }\end{array}$ & $56.40 \pm 0.06$ & $17.78 \pm 0.01$ & $2.61 \pm 0.01$ & 155 & 123 & 128 & \\
\hline $\begin{array}{l}\text { Flower } \\
\text { extract }\end{array}$ & $21.76 \pm 0.02$ & $31.45 \pm 0.06$ & $1.95 \pm 0.03$ & 82 & 34 & 53 & \\
\hline$p$-value & $<0.001$ & $<0.001$ & $<0.001$ & $<0.001$ & $<0.001$ & $<0.001$ & \\
\hline
\end{tabular}

$L^{*}$ (lightness), $a^{*}$ (greenness-redness), and $b^{*}$ (blueness-yellowness). 


\subsection{Chemical Profile}

Although A. caudatus has been the subject of previous studies, the seeds have been the most studied part of this plant. Table 2 presents the A. caudatus flowers composition in organic acids and tocopherols. Oxalic acid $(2.48 \mathrm{mg} / 100 \mathrm{~g} \mathrm{dw})$ was identified as the major organic acid, followed by shikimic acid $(0.170 \mathrm{mg} / 100 \mathrm{~g} \mathrm{dw})$. Traces of fumaric acid were also detected. Although there are no previous studies describing the organic acid profile of the studied flowers, oxalates have been described in this plant [23]. Regarding tocopherols, three of the four isoforms were detected in the studied A. caudatus flowers. $\beta$-Tocopherol was the most abundant $(0.884 \mathrm{mg} / 100 \mathrm{~g} \mathrm{dw})$, followed by the $\delta-(0.60 \mathrm{mg} / 100 \mathrm{~g} \mathrm{dw})$ and $\alpha(0.47 \mathrm{mg} / 100 \mathrm{~g} \mathrm{dw})$ vitamers. According to the literature, there is no previous data on the tocopherols composition of $A$. caudatus flower, but there are for the seeds. Bruni et al. [24,25] reported $\delta(2.17-4.88 \mathrm{mg} / 100 \mathrm{~g}), \beta(1.95-4.39 \mathrm{mg} / 100 \mathrm{~g})$ and $\alpha(1.25-3.48 \mathrm{mg} / 100 \mathrm{~g})$ tocopherols as the major vitamers in A. caudatus seeds, and $\gamma$-tocopherol $(0.06-0.22 \mathrm{mg} / 100 \mathrm{~g})$ in minor concentration. The levels of tocopherols reported for the seeds are higher than those quantified in this study for flowers, as the seeds are generally richer in lipophilic constituents. The chemical characterisation herein described contributes to the knowledge of $A$. caudatus flowers in terms of organic acids and tocopherols composition, since, to the best of the authors' knowledge, this is the first report describing these molecules in this plant matrix.

Table 2. Tocopherols and organic acids composition of A. caudatus flowers.

\begin{tabular}{cc}
\hline Organic Acids & Content $(\mathbf{g} / \mathbf{1 0 0} \mathbf{g ~ d w})$ \\
\hline Oxalic acid & $2.48 \pm 0.05$ \\
Shikimic acid & $0.170 \pm 0.003$ \\
Fumaric acid & $\operatorname{tr}$ \\
Total & $2.65 \pm 0.03$ \\
Tocopherols & Content $(\mathrm{mg} / 100 \mathrm{~g} \mathrm{dw})$ \\
$\alpha$-Tocopherol & $0.47 \pm 0.01$ \\
$\beta$-Tocopherol & $0.884 \pm 0.003$ \\
$\gamma$-Tocopherol & $\mathrm{nd}$ \\
$\delta$-Tocopherol & $0.60 \pm 0.06$ \\
Total & $1.95 \pm 0.06$ \\
\hline
\end{tabular}

tr: traces; nd: not detected.

Table 3 shows the retention times, wavelengths of maximum absorption in the visible region, mass spectral data, tentative identification, and quantification of the betacyanins detected in A. caudatus flower extract. Four compounds were tentatively identified, namely amaranthine $\left([\mathrm{H}]^{+}\right.$at $\left.\mathrm{m} / \mathrm{z} 727\right)$, isoamaranthine $\left([\mathrm{H}]^{+}\right.$at $\left.\mathrm{m} / \mathrm{z} 727\right)$, betanin $\left([\mathrm{H}]^{+}\right.$ at $\mathrm{m} / \mathrm{z} 551)$, and isobetanin $\left([\mathrm{H}]^{+}\right.$at $\left.\mathrm{m} / \mathrm{z} 551\right)$, based on data of previous studies $[26,27]$ made with plants of the same species. As far as the authors know, this is the first study reporting the betacyanins composition of $A$. caudatus flower (small flowers that make up the inflorescences) extracts.

Table 3. Betacyanins of $A$. caudatus flower extract chromatographic identification (retention time (Rt)), wavelengths of maximum absorption in the visible region $\left(\lambda_{\max }\right)$, and mass spectral data $(\mathrm{MS})$, and quantification (mg/g extract).

\begin{tabular}{ccccccc}
\hline Peak & $\mathbf{R t}(\mathbf{m i n})$ & $\boldsymbol{\lambda}_{\max }(\mathbf{n m})$ & ${\mathbf{~ H ~}]^{+} \mathbf{( m / z )}} \mathbf{M S}^{\mathbf{2}}$ & Tentative Identification & Quantification mg/g Extract \\
\hline 1 & 18.68 & 536 & 727 & $551(100), 389(40)$ & Amaranthine & $171 \pm 1$ \\
2 & 20.02 & 536 & 727 & $551(100), 389(27)$ & Isoamaranthine & $38 \pm 1$ \\
3 & 22.04 & 536 & 551 & $389(100)$ & Betanin & $1.6 \pm 0.1$ \\
4 & 23.23 & 536 & 551 & $389(100)$ & Isobetanin & $1.3 \pm 0.1$ \\
& & & & & Total & $212 \pm 1$ \\
\hline
\end{tabular}

Regarding the quantification of the compounds, it was possible to observe that peaks 1 and 2, amaranthine and isoamaranthine, respectively, represented together $98.58 \%$ of 
the total amount of betacyanins identified, with amounts of $171 \pm 1$ and $38 \pm 1 \mathrm{mg} / \mathrm{g}$ of extract, respectively. Due to the low representative quantities of peaks 3 and 4 , betanin and isobetanin, respectively, were not taken into consideration for the optimisation studies performed by UAE.

\subsection{Bioactive Properties}

The antihaemolytic activity of the $A$. caudatus flower extract was tested by the OxHLIA assay. According to the obtained results (Table 4), extract concentrations of $29 \mu \mathrm{g} / \mathrm{mL}$ and $111 \mu \mathrm{g} / \mathrm{mL}$ were required to protect half the erythrocyte population from the oxidative haemolytic induced by $\mathrm{AAPH}$, a temperature-dependent free radical initiator, for $\Delta t$ of 60 and $120 \mathrm{~min}$, respectively. Trolox, the positive control used, was more effective in protecting the erythrocyte membranes than the flower extract, with $\mathrm{IC}_{50}$ values of $16.6 \mu \mathrm{g} / \mathrm{mL}$ and $44 \mu \mathrm{g} / \mathrm{mL}$ for $\Delta t$ of 60 and $120 \mathrm{~min}$, respectively. However, it should be noted that the trolox is a pure antioxidant compound, whereas the tested extract is a complex mixture of different constituents, some of which have no activity. In addition, it was also found that the antioxidants present in the flower extract were more effective for a period of just $60 \mathrm{~min}$ than for $120 \mathrm{~min}$. Antioxidants, such as betacyanins and tocopherols, probably acted and were depleted at an earlier stage of the in vitro assay. In a previous study, Jo et al. [22] evaluated the radical scavenging activity of $A$. caudatus flower extract obtained by hot water extraction and reported it as a promising source of antioxidants. However, it is difficult to compare these results with those of the present study due to the different mechanisms of action of the performed antioxidant assays.

Table 4. Antihaemolytic and antibacterial activities of the A. caudatus flower extract and positive controls.

\begin{tabular}{|c|c|c|c|c|c|c|c|c|}
\hline & \multicolumn{2}{|c|}{ Flower Extract } & \multicolumn{6}{|c|}{ Positive Controls } \\
\hline Antihaemolytic activity $\left(\mathrm{IC}_{50}, \mu \mathrm{g} / \mathrm{mL}\right)$ & \multirow{3}{*}{\multicolumn{2}{|c|}{$\begin{array}{c}29 \pm 1 \\
111 \pm 5\end{array}$}} & \multicolumn{6}{|c|}{ Trolox } \\
\hline OxHLIA, $\Delta t 60 \mathrm{~min}$ & & & & & \multirow{2}{*}{\multicolumn{2}{|c|}{$\begin{aligned} 19.6 & \pm 0.8 \\
41 & \pm 1\end{aligned}$}} & & \\
\hline OxHLIA, $\Delta t 120 \mathrm{~min}$ & & & & & & & & \\
\hline \multirow[t]{2}{*}{$\begin{array}{c}\text { Antibacterial activity } \\
\text { (MIC and } \mathrm{MBC}, \mathrm{mg} / \mathrm{mL} \text { ) }\end{array}$} & & & \multicolumn{2}{|c|}{$\begin{array}{l}\text { Ampicillin } \\
(20 \mathrm{mg} / \mathrm{mL})\end{array}$} & \multicolumn{2}{|c|}{$\begin{array}{l}\text { Imipenem } \\
(1 \mathrm{mg} / \mathrm{mL})\end{array}$} & \multicolumn{2}{|c|}{$\begin{array}{l}\text { Vancomycin } \\
(1 \mathrm{mg} / \mathrm{mL})\end{array}$} \\
\hline & MIC & $\mathrm{MBC}$ & MIC & MBC & MIC & MBC & MIC & MBC \\
\hline \multicolumn{9}{|l|}{ Gram-negative bacteria } \\
\hline Escherichia coli & 10 & $>20$ & $<0.15$ & $<0.15$ & $<0.0078$ & $<0.0078$ & nt & nt \\
\hline Klebsiella pneumoniae & 5 & $>20$ & 10 & 20 & $<0.0078$ & $<0.0078$ & nt & nt \\
\hline Morganella morganii & 5 & $>20$ & 20 & $>20$ & $<0.0078$ & $<0.0078$ & nt & nt \\
\hline Proteus mirabilis & 20 & $>20$ & $<015$ & $<0.15$ & $<0.0078$ & $<0.0078$ & nt & nt \\
\hline Pseudomonas aeruginosa & 20 & $>20$ & $>20$ & $>20$ & 0.5 & 1 & nt & nt \\
\hline \multicolumn{9}{|l|}{ Gram-positive bacteria } \\
\hline Enterococcus faecalis & 5 & $>20$ & $<0.15$ & $<0.15$ & nt & nt & $<0.0078$ & $<0.0078$ \\
\hline Listeria monocytogenes & $>20$ & $>20$ & $<0.15$ & $<0.15$ & $<0.0078$ & $<0.0078$ & nt & nt \\
\hline MRSA & 5 & $>20$ & $<0.15$ & $<0.15$ & nt & nt & 0.25 & 0.5 \\
\hline
\end{tabular}

MRSA—methicillin Resistant Staphylococcus aureus; for antihemolytic activity, statistical differences $(p<0.001)$ between samples were found when applying a Student's $t$-test. MIC: minimum inhibitory concentration; MBC: minimum bactericidal concentration; nt: not tested.

Regarding the antibacterial activity (Table 4), the flower extract showed activity against most of the tested microorganisms, with the exception of L. monocytogenes that was not inhibited at the maximum tested concentration of $20 \mathrm{mg} / \mathrm{mL}$. In general, the tested Gramnegative bacteria showed higher susceptibility to the flower extract. In some cases, the MIC values shown by the extract are lower. For instance, the extract concentrations needed to inhibit K. pneumoniae and M. morganii were 5 and $10 \mathrm{mg} / \mathrm{mL}$, respectively, while the concentrations of ampicillin needed to inhibit these microorganisms were $10 \mathrm{mg} / \mathrm{mL}$ and $20 \mathrm{mg} / \mathrm{mL}$, respectively. The obtaining of natural extracts with a similar/higher antibacterial potential than the commonly used antibiotics is of high relevance, given the growing inefficacy of antibiotics against bacterial strains. 
For this species, regarding the bioactivities, the data in the literature refer mostly to the seeds of this plant, which are the plant parts that have aroused the most interest so far. In a review study conducted by Martinez-Lopez et al. [23], the authors state that the seeds contain a large number of bioactivities such as anthelmintic, antinociceptive, antipyretic, anticancer, antiallergenic, antidiabetic, stimulation of the immune system, cardioprotective, hepatoprotective and antibacterial activities. According to Maiyo et al. [28], A. caudatus fresh leaf extracts where active against E. coli, Salmonella typhi, Prooteus mirabilis, Staphylococcus aureus, and Bacillus sp.

Regarding the toxicity for normal cells PLP2, the extract revealed no toxicity at a maximum of $400 \mu \mathrm{g} / \mathrm{mL}$, allowing the attainment of an indication of its safety. Therefore, other in vitro and in vivo assays are needed to validate these results.

Additionally, regarding the described bioactivities, it should be noted that these results refer to the seeds of this species, and for that reason different results are obtained compared to the present work. These differences can be explained due to differences in the chemical composition of the different parts of the plant, since in the present study, the main focus is the recovery of colouring compounds (betacyanins) and the analysis of their ability to promote biological properties as an extra benefit.

\subsection{Optimisation of the Extraction Process}

Betacyanins can be recovered from plant materials using conventional solid-liquid extraction methods or novel extraction techniques as alternatives to the conventional ones to increase the betalains' yield in a more efficient and sustainable way. In recent years, several studies have been carried out to optimise the extraction of these pigments from various plant matrices using different methodologies. In this study, the suitability of UAE for extracting betacyanins from $A$. caudatus was investigated and optimised. This timesaving method has already been successfully applied by the authors to recover betacyanins from globe amaranth (Gomphrena globosa L.) flowers [12,16]. It allows the improvement of the extraction yield due to the acoustic cavitation effect that enhances mass transfer phenomena $[29,30]$. However, the energy applied to promote the plant cell disruption can affect the molecules integrity if applied at high intensity, as well as the other independent variables used in the process intensification. The most relevant ones should be combined in experimental RSM designs, in order to access interactive effects and to optimise extraction process with a low number of executions.

\subsubsection{Experimental Data for Process Optimisation}

As presented in Table 5, the extraction yield (extract weight) achieved with the 18 runs of the CCD design was quite low and ranged from 1.31 to $2.27 \%(w / w)$. In turn, as discussed above, amaranthine and isoamaranthine were the major betacyanins identified in A. caudatus flowers. The amaranthine levels ranged from 48.87 to $55.70 \mathrm{mg} / \mathrm{g}$ plant material, while the isoamaranthine levels ranged from 16.52 to $19.56 \mathrm{mg} / \mathrm{g}$ plant material. In both cases, the lower and higher contents were obtained with the runs 1 and 4 (which combined the independent variables at medium-low $(-1)$ and medium-high $(+1)$ levels) and 2 and 3 (which combined the independent variables at medium-high $(+1)$ and medium-low $(-1)$ levels), respectively. For the first case, this observation indicates that the combined variables intensity may not be sufficient to promote the extraction, due to the short time and low ultrasonic power involved, or that, if both variables are applied at a higher intensity, they may lead to pigment degradation. According to the results of runs 2 and 3, it is preferable to use a longer processing time combined with a lower ultrasonic power, or a shorter sonication time with a higher ultrasonic power to promote extraction without causing degradation. The experimental runs achieved with the fourth response variable (total betacyanins) showed the same trend, as it resulted from the sum of all betacyanins quantified in the aqueous flower extract, where amaranthine $(\sim 70 \%)$ and isoamaranthine $(\sim 24 \%)$ were major compounds. Indeed, as betanin and isobetanin were detected at 
lower concentration ( $\sim 6 \%$ of the total content), the optimisation was performed only for amaranthine and isoamaranthine in an individual way (Table 5).

Table 5. Experimental results for the betacyanins content obtained with the 18 runs of the central composite design (CCD) design.

\begin{tabular}{|c|c|c|c|c|c|c|}
\hline \multirow[t]{2}{*}{ Runs } & \multicolumn{2}{|c|}{ Experimental Domain } & \multicolumn{4}{|c|}{ Experimental Responses } \\
\hline & Time (min) & Power (W) & $\begin{array}{l}\text { Extraction Yield } \\
(\%, w / w)\end{array}$ & $\begin{array}{c}\text { Amaranthine } \\
\text { (mg/g Plant } \\
\text { Material) }\end{array}$ & $\begin{array}{c}\text { Isoamaranthine } \\
\text { (mg/g Plant } \\
\text { Material) }\end{array}$ & $\begin{array}{c}\text { Total Betacyanins * } \\
\text { (mg/g Plant } \\
\text { Material) }\end{array}$ \\
\hline 1 & $-1(4.5)$ & $-1(44.4)$ & 1.31 & 48.87 & 16.52 & 69.55 \\
\hline 2 & $+1(41.5)$ & $-1(44.4)$ & 1.54 & 55.46 & 18.85 & 78.94 \\
\hline 3 & $-1(4.5)$ & $+1(460.6)$ & 1.91 & 55.70 & 19.56 & 79.90 \\
\hline 4 & $+1(41.5)$ & $+1(460.6)$ & 2.20 & 48.90 & 17.16 & 70.48 \\
\hline 5 & $-1.19(1)$ & $0(252.5)$ & 1.42 & 52.26 & 17.84 & 74.36 \\
\hline 6 & $-1.19(1)$ & $0(252.5)$ & 1.45 & 52.26 & 18.64 & 75.41 \\
\hline 7 & $+1.19(45)$ & $0(252.5)$ & 1.70 & 51.53 & 17.76 & 73.77 \\
\hline 8 & $+1.19(45)$ & $0(252.5)$ & 2.03 & 52.39 & 18.34 & 75.32 \\
\hline 9 & $0(23)$ & $-1.19(5)$ & 1.60 & 52.40 & 17.87 & 74.83 \\
\hline 10 & $0(23)$ & $-1.19(5)$ & 1.44 & 52.41 & 18.11 & 75.03 \\
\hline 11 & $0(23)$ & $+1.19(500)$ & 1.85 & 51.85 & 17.76 & 73.84 \\
\hline 12 & $0(23)$ & $+1.19(500)$ & 2.27 & 51.85 & 18.45 & 74.79 \\
\hline 13 & $0(23)$ & $0(252.5)$ & 1.74 & 51.87 & 17.86 & 74.00 \\
\hline 14 & $0(23)$ & $0(252.5)$ & 1.71 & 53.34 & 18.39 & 76.31 \\
\hline 15 & $0(23)$ & $0(252.5)$ & 1.85 & 50.67 & 17.87 & 73.06 \\
\hline 16 & $0(23)$ & $0(252.5)$ & 1.80 & 52.34 & 18.16 & 75.22 \\
\hline 17 & $0(23)$ & $0(252.5)$ & 1.75 & 50.06 & 17.29 & 71.23 \\
\hline 18 & $0(23)$ & $0(252.5)$ & 1.63 & 53.32 & 18.46 & 76.23 \\
\hline
\end{tabular}

* Sum of the amaranthine, isoamaranthine, betanin, and isobetanin contents.

\subsubsection{Models Fitting and Statistical Verification}

The response values in Table 5 were fitted to a polynomial regression model using the Design-Expert software, but just the significant parameters (assessed at a 95\% confidence level) were used in the construction of the predictive models. The results of analysis of variance and regression analyses are presented in Supplementary Material Table S2, while the resulting polynomial models are shown in Equations (1)-(4).

$$
\begin{gathered}
Y_{(\text {Yield })}=1.73+0.186 t+0.236 P\left[\mathrm{R}^{2}=0.8638 ; \mathrm{R}^{2} \text { adj }=0.8457\right] \\
Y_{(\text {Amaranthine })}=52.08-3.35 t P\left[\mathrm{R}^{2}=0.8178 ; \mathrm{R}^{2}{ }_{\text {adj }}=0.7788\right] \\
Y_{(\text {Isoamaranthine })}=18.05-1.18 t P\left[\mathrm{R}^{2}=0.7526 ; \mathrm{R}^{2}{ }_{\text {adj }}=0.7000\right] \\
Y_{(\text {Total betacyanins })}=75.57-4.70 t P\left[\mathrm{R}^{2}=0.7881 ; \mathrm{R}^{2}{ }_{\text {adj }}=0.7439\right]
\end{gathered}
$$

In the mathematical models developed for each response variable, the coefficients illustrate the effect of the independent variables and/or their interaction. The parametric values represent the expected effect on the response when changing one factor value. Therefore, the higher these values, the more significant the weight of the respective variable will be. In addition, the negative sign represents an antagonistic interaction between variables [30]. In each model equation, the intercept corresponds to the overall average response of the 18 runs of the CCD design (Table 5). As discussed above, these values are low for the extraction yield (extract weight) and particularly higher for amaranthine and total betacyanin contents.

The four mathematical models had a non-significant lack-of-fit $(p>0.05)$ and an adequate precision $>15$, which indicates that the model equations adequately describe the effects of the variables $t$ and $P$ on $Y_{1}-Y_{3}$ [31]. The coefficients $R^{2}$ and $R^{2}$ adj were 
higher than 0.75 and 0.70 for all models, respectively (Equations (1)-(4)), showing that the variability of each response can be explained by the extraction process variables. Value $>15.4$ were obtained for adequate precision (Supplementary Material Table S2). Therefore, the constructed model equations were statistically validated and used in the following steps to predict the optimal UAE conditions.

Based on Equation (1), it can be observed that the extraction yield is significantly affected by both independent variables through linear effects, while, for betacyanins, Equations (2)-(4) illustrate that the extraction process is affected by negative interactive effects between the variables. These results support the use of RSM as an optimisation tool, since the one-factor-at-a-time approaches do not evaluate interactive effects.

\subsubsection{Effect of the Independent Variables on the Target Responses}

The 3D response surface graphs generated to illustrate the effect of the two independent variables on the extraction yield and total betacyanin contents are presented in Figure 1 . The extraction yield was positively affected by the two independent variables involved in the extraction process, mainly by ultrasonic power. As shown in Figure 1, the increase in extraction time and ultrasonic power led to a linear increase in response values. On the other hand, sonication of the flower sample at low power for short periods of time was not sufficient to promote the recovery of betacyanins, while processing at high ultrasonic power over longer periods appeared to have caused pigment degradation. The red coloured response surface areas show two possible response optimums, corresponding to the use of short processing times at high ultrasonic power, and vice versa. Thus, based on the 3D representations, it is possible to conclude that the greater extract weight obtained with the combination of extreme processing conditions does not translate to a greater extraction of betacyanin pigments.

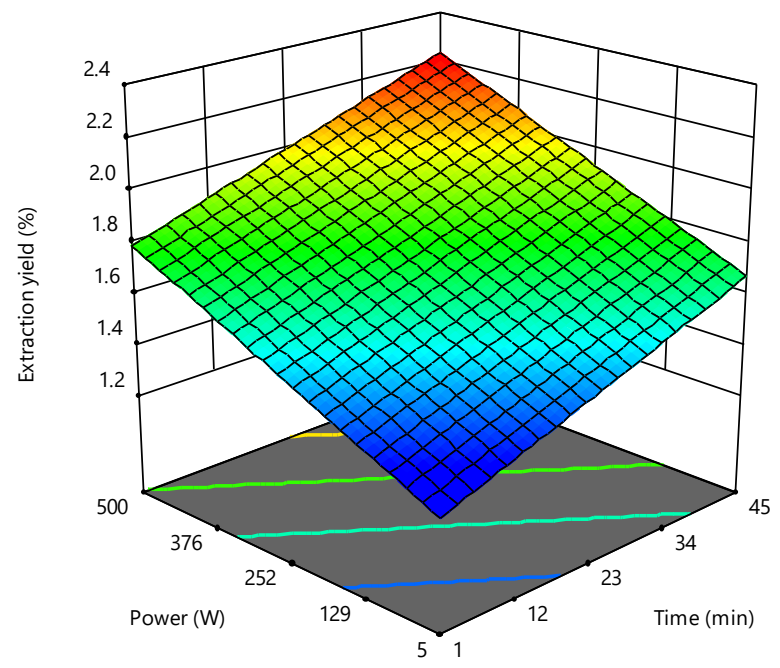

(a)

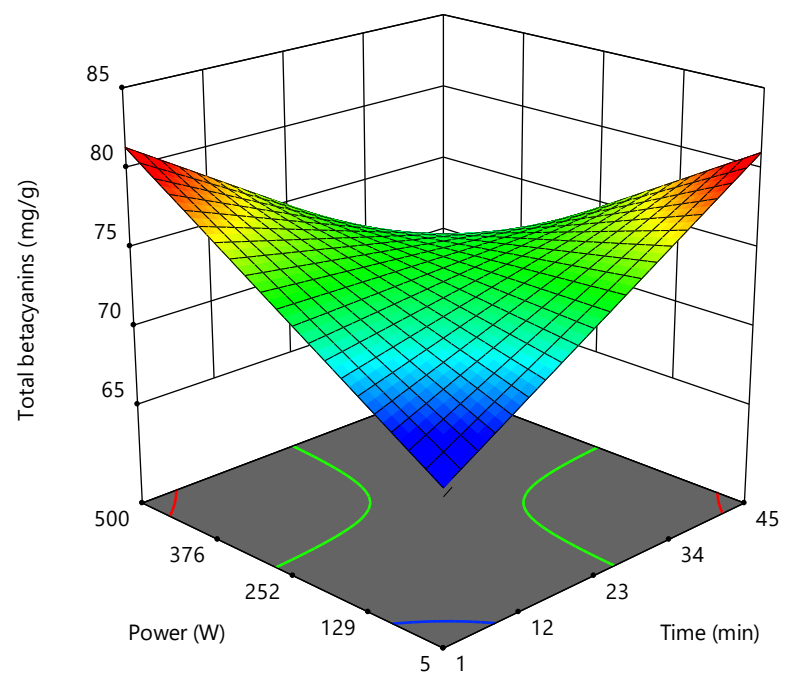

(b)

Figure 1. Response surface graph illustrating the binary effects of the two independent variables on (a) extraction yield (\%, $w / w)$ and (b) total betacyanins content ( $\mathrm{mg} / \mathrm{g}$ plant material) obtained from A. caudatus.

According to previous reports, the betacyanin stability can be affected by several factors such as temperature, $\mathrm{pH}$, light intensity, and presence of oxygen and enzymes, among others [32]. Therefore, the intensification factors to be used in extraction processes must be applied in sufficient intensity to promote the pigments' recovery, but that does not harm its integrity. In fact, when exposed to extreme processing conditions, betacyanins can undergo isomerisation, deglycosylation, or decarboxylation depending on their structural features [33]. 


\subsubsection{Optimal Extraction Conditions}

The optimal extraction conditions predicted with the theoretical model Equations (1)-(4) for each response variable are presented in Supplementary Material Table S3 and can be summarised as follows: (i) $2.14 \pm 0.05 \%$ extract weight $(w / w)$ is obtained by processing the plant material at $474 \mathrm{~W}$ for $38.5 \mathrm{~min}$; (ii) $55.2 \pm 0.6 \mathrm{mg} / \mathrm{g}$ pant material of amaranthine are obtained by processing at $443 \mathrm{~W}$ for $4.2 \mathrm{~min}$; (iii) $19.4 \pm 0.3 \mathrm{mg} / \mathrm{g}$ pant material of isoamaranthine are obtained by processing at $473 \mathrm{~W}$ for $6.49 \mathrm{~min}$; and (iv) $79.2 \pm 0.9 \mathrm{mg} / \mathrm{g}$ pant material of total betacyanins are obtained by processing at $454 \mathrm{~W}$ for $4.8 \mathrm{~min}$. Overall, the recovery of betacyanins required a shorter extraction time than the extraction yield, while high ultrasonic powers were involved in all cases. In this study, the optimal extraction conditions that maximise both the extraction yield and the total betacyanin content as much as possible were also determined (Supplementary Material Table S3), since it is important to achieve a high extract weight with high levels of colouring compounds for further application in the industrial sector as natural colorants. Based on this second optimisation, it was concluded that 13.3 min sonication at $500 \mathrm{~W}$ were the optimal UAE conditions to simultaneously maximise the response variables $(1.92 \pm 0.05 \%$ extract and $77.6 \pm 0.7 \mathrm{mg} / \mathrm{g}$ of total betacyanins).

A previous study performed by the authors in globe amaranth flowers [16], $22 \mathrm{~min}$ sonication at $500 \mathrm{~W}(20 \mathrm{kHz})$ was described as the UAE conditions that maximise the aqueous extraction of betacyanins. The longer processing time can be justified by the intrinsic nature of the plant material and by the different betacyanin compounds. One other author [13] described $37 \mathrm{~min}$ as the optimal MAE time for the pigments' recovery from Bougainvillea glabra Choisy flowers, when applying a lower ultrasonic power of $88 \mathrm{~W}$ $(20 \mathrm{kHz})$ and water at $55^{\circ} \mathrm{C}$. In turn, Melgar et al., [34] and Ahmed et al. [35] reported timesaving UAE processes for extraction of betalains from prickly pear (Opuntia engelmannii Salm-Dyck ex Engelm.) peel (2.5 min processing at $2 \mathrm{kHz}$ and $200 \mathrm{rpm}$, using $34.6 \%$ methanol at $\mathrm{pH}$ 7) and red amaranth (Amaranthus cruentus L.) leafy part (5 min sonication at $35 \mathrm{kHz}$, using water at $70^{\circ} \mathrm{C}$ ).

\section{Conclusions}

The chromatographic analyses allowed characterisation of the profile in organic acids, tocopherols, and betacyanins of the underexploited A. caudatus flowers. The aqueous extract display antihemolytic activity and antibacterial effects against foodborne bacteria. Furthermore, it has no hepatotoxicity to PLP2 cells at the tested concentrations, which represents a positive clue regarding safety issues. Moreover, given the high amounts and colouring capacity of betacyanins, the UAE of these pigments was optimised by RSM in order to obtain a betacyanin-rich purple extract. The UAE process was affected by both independent variables, extraction time and ultrasonic power. The predictive models were successfully fitted to the experimental data and validated based on different statistical criteria. With $13.3 \mathrm{~min}$ sonication at $500 \mathrm{~W}$, it was possible to reach an overall maximum of $1.92 \%$ of extract weight $(w / w)$ and $77.6 \mathrm{mg} / \mathrm{g}$ of total betacyanins. This betacyaninrich extract can be highlighted as a promising natural colorant for application mainly in the food sector as an alternative to the controversial artificial food colorants since this ingredient can also act as a preservative and health promoter due to its antioxidant and antibacterial properties.

Supplementary Materials: The following are available online at https: / www.mdpi.com/article / 10.3390/foods10040779/s1, Table S1: Natural and coded values of the independent variables used in the five-level CCD design implemented to optimise the extraction process of betacyanins from Amaranthus using RSM. Table S2: Parametric coefficients and statistical information of the fitting procedure of the models. Parametric superscripted 1 and 2 stands for the variables time and ultrasonic power, respectively. Table S3: Optimal extraction conditions in natural values that maximise the response values. 
Author Contributions: Investigation: C.L.R., V.X., M.I.D., J.P., R.C.C., writing-original draft: C.L.R, M.I.D., J.P., S.A.H., formal analysis: J.P., supervision: P.M., L.B., conceptualisation: S.A.H., L.B., writing - review and editing: S.A.H., J.P., funding acquisition: I.C.F.R.F. All authors have read and agreed to the published version of the manuscript.

Funding: This research was funded by the Portuguese Foundation for Science and Technology (FCT) and European Regional Development Fund (ERDF) through the Regional Operational Program North 2020, within the scope of project Mobilizador Norte-01-0247-FEDER-024479: ValorNatural ${ }^{\circledR}$ and GreenHealth (Norte-01-0145-FEDER-000042).

Institutional Review Board Statement: Not applicable.

Data Availability Statement: Data is contained within the Supplementary Material.

Acknowledgments: The authors are grateful to the Foundation for Science and Technology (FCT, Portugal) for financial support by national funds FCT/MCTES to CIMO (UIDB/00690/2020). To FCT for the C.L. Roriz PhD's grant (SFRH/BD/117995/2016). L. Barros, M.I Dias, and R.C. Calhelha thank the national funding by FCT-Foundation for Science and Technology, P.I., through the institutional scientific employment program-contract for their contracts, and S.A. Heleno (CEECIND/03040/2017) and J. Pinela (CEECIND/01011/2018) through the individual scientific employment program-contract. The authors are also grateful to the European Regional Development Fund (ERDF) through the Regional Operational Program North 2020, within the scope of project Mobilizador Norte-01-0247FEDER-024479: ValorNatural ${ }^{\circledR}$ and GreenHealth (Norte-01-0145-FEDER-000042. Finally, P. Morales is also grateful to UCM ALIMNOVA Research Group (Ref. 951505) and to Spanish Ministry of Science and Innovation (PID-2019-109365RA-I00).

Conflicts of Interest: The authors declare no conflict of interest.

\section{References}

1. Calabrò, S. Plant Secondary Metabolites. Rumen Microbiol. Evol. Revolut. 2015, 153-159. [CrossRef]

2. Zhong, J.J. Plant Secondary Metabolites, 3rd ed.; Elsevier: Amsterdam, The Netherlands, 2011; Volume 3, ISBN 9780080885049.

3. Verma, N.; Shukla, S. Impact of Various Factors Responsible for Fluctuation in Plant Secondary Metabolites. J. Appl. Res. Med. Aromat. Plants 2015, 2, 105-113. [CrossRef]

4. Stintzing, F.C.; Carle, R. Functional Properties of Anthocyanins and Betalains in Plants, Food, and in Human Nutrition. Trends Food Sci. Technol. 2004, 15, 19-38. [CrossRef]

5. Li, Y.; Kong, D.; Fu, Y.; Sussman, M.R.; Wu, H. The Effect of Developmental and Environmental Factors on Secondary Metabolites in Medicinal Plants. Plant Physiol. Biochem. 2020, 148, 80-89. [CrossRef] [PubMed]

6. Castrillón-Arbeláez, P.A.; Délano Frier, J.P. Secondary Metabolism in Amaranthus spp.-A Genomic Approach to Understand Its Diversity and Responsiveness to Stress in Marginally Studied Crops with High Agronomic Potential. Abiotic Biot. Stress Plants Recent Adv. Futur. Perspect. 2016. [CrossRef]

7. Martins, N.; Roriz, C.L.; Morales, P.; Barros, L.; Ferreira, I.C.F.R. Food Colorants: Challenges, Opportunities and Current Desires of Agro-industries to Ensure Consumer Expectations and Regulatory Practices. Trends Food Sci. Technol. 2016, 52, 1-15. [CrossRef]

8. Kaur, S.; Singh, N.; Rana, J.C. Amaranthus Hypochondriacus and Amaranthus caudatus Germplasm: Characteristics of Plants, Grain and Flours. Food Chem. 2010, 123, 1227-1234. [CrossRef]

9. Peter, K.; Gandhi, P. Rediscovering the Therapeutic Potential of Amaranthus Species: A Review. Egypt. J. Basic Appl. Sci. 2017, 4, 196-205. [CrossRef]

10. Roriz, C.L.; Barros, L.; Prieto, M.A.; Círić, A.; Soković, M.; Morales, P.; Ferreira, I.C.F.R. Enhancing the Antimicrobial and Antifungal Activities of a Coloring Extract Agent Rich in Betacyanins Obtained from: Gomphrena globosa L. Flowers. Food Funct. 2018, 9, 6205-6217. [CrossRef]

11. Raiten, D.J.; Darnton-Hill, I.; Tanumihardjo, S.A.; Suchdev, P.S.; Udomkesmalee, E.; Martinez, C.; Mazariegos, D.I.; Mofu, M.; Kraemer, K.; Martinez, H. Perspective: Integration to Implementation (I-to-I) and the Micronutrient Forum - Addressing the Safety and Effectiveness of Vitamin A Supplementation. Adv. Nutr. 2020, 11, 185-199. [CrossRef]

12. Roriz, C.L.; Barros, L.; Prieto, M.A.; Morales, P.; Ferreira, I.C.F.R. Floral Parts of Gomphrena globosa L. as a Novel Alternative Source of Betacyanins: Optimization of the Extraction Using Response Surface Methodology. Food Chem. 2017, 229, 223-234. [CrossRef]

13. Prakash Maran, J.; Priya, B.; Nivetha, C.V. Optimization of Ultrasound-assisted Extraction of Natural Pigments from Bougainvillea glabra Flowers. Ind. Crop. Prod. 2015, 63, 182-189. [CrossRef]

14. Ramli, N.S.; Ismail, P.; Rahmat, A. Influence of Conventional and Ultrasonic-assisted Extraction on Phenolic Contents, Betacyanin Contents, and Antioxidant Capacity of Red Dragon Fruit (Hylocereus polyrhizus). Sci. World J. 2014, 2014. [CrossRef]

15. Fathordoobady, F.; Mirhosseini, H.; Selamat, J.; Manap, M.Y.A. Effect of Solvent Type and Ratio on Betacyanins and Antioxidant Activity of Extracts from Hylocereus polyrhizus Flesh and Peel by Supercritical Fluid Extraction and Solvent Extraction. Food Chem. 2016, 202, 70-80. [CrossRef] [PubMed] 
16. Roriz, C.L.; Barros, L.; Prieto, M.A.; Barreiro, M.F.; Morales, P.; Ferreira, I.C.F.R. Modern Extraction Techniques Optimized to Extract Betacyanins from Gomphrena globosa L. Ind. Crop. Prod. 2017, 105, 29-40. [CrossRef]

17. Pereira, C.; Barros, L.; Carvalho, A.M.; Ferreira, I.C.F.R. Use of UFLC-PDA for the Analysis of Organic Acids in Thirty-Five Species of Food and Medicinal Plants. Food Anal. Methods 2013, 6, 1337-1344. [CrossRef]

18. Barros, L.; Pereira, E.; Calhelha, R.C.; Dueñas, M.; Carvalho, A.M.; Santos-Buelga, C.; Ferreira, I.C.F.R. Bioactivity and Chemical Characterization in Hydrophilic and Lipophilic Compounds of Chenopodium ambrosioides L. J. Funct. Foods 2013, 5, 1732-1740. [CrossRef]

19. Silva de Sá, I.; Peron, A.P.; Leimann, F.V.; Bressan, G.N.; Krum, B.N.; Fachinetto, R.; Pinela, J.; Calhelha, R.C.; Barreiro, M.F.; Ferreira, I.C.F.R.F.R.; et al. In vitro and in vivo Evaluation of Enzymatic and Antioxidant Activity, Cytotoxicity and Genotoxicity of Curcumin-loaded Solid Dispersions. Food Chem. Toxicol. 2019, 125, 29-37. [CrossRef] [PubMed]

20. Pires, T.C.S.P.; Dias, M.I.; Barros, L.; Alves, M.J.; Oliveira, M.B.P.P.; Santos-Buelga, C.; Ferreira, I.C.F.R. Antioxidant and Antimicrobial Properties of Dried Portuguese Apple Variety (Malus domestica Borkh. cv Bravo de Esmolfe). Food Chem. 2018, 240, 701-706. [CrossRef]

21. Guimarães, R.; Barros, L.; Dueñas, M.; Calhelha, R.C.; Carvalho, A.M.; Santos-Buelga, C.; Queiroz, M.J.R.P.; Ferreira, I.C.F.R. Nutrients, Phytochemicals and Bioactivity of Wild Roman Chamomile: A Comparison between the Herb and Its Preparations. Food Chem. 2013, 136, 718-725. [CrossRef]

22. Jo, H.J.; Chung, K.H.; Yoon, J.A.; Lee, K.J.; Song, B.C.; An, J.H. Radical Scavenging Activities of Tannin Extracted from Amaranth (Amaranthus caudatus 1.). J. Microbiol. Biotechnol. 2015, 25, 795-802. [CrossRef]

23. Martinez-Lopez, A.; Millan-Linares, M.C.; Rodriguez-Martin, N.M.; Millan, F.; Montserrat-de la Paz, S. Nutraceutical Value of Kiwicha (Amaranthus caudatus L.). J. Funct. Foods 2020, 65, 103735. [CrossRef]

24. Bruni, R.; Guerrini, A.; Scalia, S.; Romagnoli, C.; Sacchetti, G. Rapid Techniques for the Extraction of Vitamin E Isomers from Amaranthus caudatus Seeds: Ultrasonic and Supercritical Fluid Extraction. Phytochem. Anal. 2002, 13, 257-261. [CrossRef]

25. Bruni, R.; Medici, A.; Guerrini, A.; Scalia, S.; Poli, F.; Muzzoli, M.; Sacchetti, G. Wild Amaranthus caudatus Seed Oil, a Nutraceutical Resource from Ecuadorian Flora. J. Agric. Food Chem. 2001, 49, 5455-5460. [CrossRef] [PubMed]

26. Stintzing, F.C.; Kammerer, D.; Schieber, A.; Adama, H.; Nacoulma, O.G.; Carle, R. Betacyanins and Phenolic Compounds from Amaranthus spinosus L. and Boerhavia erecta L. Z. Naturforsch. Sect. C J. Biosci. 2004, 59, 1-8. [CrossRef] [PubMed]

27. Biswas, M.; Das, S.S.; Dey, S. Establishment of a Stable Amaranthus tricolor Callus Line for Production of Food Colorant. Food Sci. Biotechnol. 2013, 22, 1-8. [CrossRef]

28. Chopra, I. The Increasing Use of Silver-based Products as Antimicrobial Agents: A Useful Development or a Cause for Concern? J. Antimicrob. Chemother. 2007, 59, 587-590. [CrossRef]

29. Pinela, J.; Prieto, M.A.; Pereira, E.; Jabeur, I.; Barreiro, M.F.; Barros, L.; Ferreira, I.C.F.R. Optimization of Heat- and Ultrasoundassisted Extraction of Anthocyanins from Hibiscus sabdariffa Calyces for Natural Food Colorants. Food Chem. 2019, $275,309-321$. [CrossRef]

30. Rocha, R.; Pinela, J.; Abreu, R.M.V.; Añibarro-Ortega, M.; Pires, T.C.S.P.; Saldanha, A.L.; Alves, M.J.; Nogueira, A.; Ferreira, I.C.F.R.; Barros, L. Extraction of Anthocyanins from Red Raspberry for Natural Food Colorants Development: Processes Optimization and in vitro Bioactivity. Processes 2020, 8, 1447. [CrossRef]

31. Iberahim, N.; Sethupathi, S.; Goh, C.L.; Bashir, M.J.K.; Ahmad, W. Optimization of Activated Palm Oil Sludge Biochar Preparation for Sulphur Dioxide Adsorption. J. Environ. Manag. 2019, 248, 109302. [CrossRef]

32. Miguel, M.G. Betalains in Some Species of the Amaranthaceae Family: A Review. Antioxidants 2018, 7, 53. [CrossRef] [PubMed]

33. Manchali, S.; Chidambara Murthy, K.N.; Nagaraju, S.; Neelwarne, B. Stability of Betalain Pigments of Red Beet. In Red Beet Biotechnology: Food and Pharmaceutical Applications; Neelwarne, B., Ed.; Springer: New York, NY, USA, 2012 ; pp. 55-74.

34. Melgar, B.; Dias, M.I.; Barros, L.; Ferreira, I.C.F.R.; Rodriguez-Lopez, A.D.; Garcia-Castello, E.M. Ultrasound and Microwave Assisted Extraction of Opuntia Fruit Peels Biocompounds: Optimization and Comparison Using RSM-CCD. Molecules 2019, 24, 3618. [CrossRef] [PubMed]

35. Ahmed, M.; Ramachandraiah, K.; Jiang, G.H.; Eun, J.B. Effects of Ultra-sonication and Agitation on Bioactive Compounds and Structure of Amaranth Extract. Foods 2020, 9, 1116. [CrossRef] [PubMed] 